\title{
Botany
}

\section{Physical defenses and herbivory vary more within plants than among plants in the tropical understory shrub Piper polytrichum}

\begin{tabular}{|r|l|}
\hline Journal: & Botany \\
\hline Manuscript ID & cjb-2018-0160.R1 \\
\hline Manuscript Type: & Article \\
\hline Date Submitted by the & 22-Oct-2018 \\
\hline $\begin{aligned} \text { Complete List of Authors: } \\
\text { Ketzel, William; Michigan State University, Department of Entomology; } \\
\text { Michigan State University, Ecology, Evolutionary Biology, and Behavior } \\
\text { Program } \\
\text { Meek, Mariah; Michigan State University, Department of Integrative } \\
\text { Biology; Michigan State University, Ecology, Evolutionary Biology, and } \\
\text { Behavior Program }\end{aligned}$ & $\begin{array}{l}\text { intraspecific trait variation, herbivory, Piper polytrichum, Piperaceae, } \\
\text { plant defense }\end{array}$ \\
\hline $\begin{array}{r}\text { Is the invited manuscript for } \\
\text { consideration in a Special } \\
\text { Issue? : }\end{array}$ & $\begin{array}{r}\text { Not applicable (regular submission) } \\
\hline\end{array}$ \\
\hline
\end{tabular}

\section{SCHOLARONE \\ Manuscripts}


Physical defenses and herbivory vary more within plants than among plants in the tropical understory shrub Piper polytrichum

\author{
William C. Wetzel ${ }^{1,2,4,5}$ and Mariah H. Meek $2,3,4$
}

${ }^{1}$ Department of Entomology, Michigan State University, East Lansing, MI, USA 48824

${ }^{2}$ Ecology, Evolutionary Biology, and Behavior Program, Michigan State University, East

Lansing, MI, USA 48824

${ }^{3}$ Department of Integrative Biology, Michigan State University, East Lansing, MI, USA 48824

${ }^{4} \mathrm{AgBioResearch}$, Michigan State University, East Lansing, MI, USA 48824

${ }^{5}$ Corresponding author email: wcwetzel@msu.edu

Running head: Subindividual trait variation and herbivory 


\begin{abstract}
There is a growing appreciation that much of the trait variation within plant species is represented within individuals, for example, occurring among leaves within a plant. Subindividual variation is predicted to have key ecological consequences, but empirical understanding of how subindividual variation relates to species interactions, such as herbivory, is limited. We measured two physical defenses and herbivore damage on multiple leaves within individual plants of Piper polytrichum (Piperaceae), a tropical understory shrub. We partitioned variance among- and within-plants and quantified patterns of trait and damage variation vis-à-vis leaf size and architectural position. We found that variance was considerably higher within plants than among plants for toughness (97\%) and trichome density (57\%), and that herbivore damage also varied most within plants (74\%). Surprisingly, leaf position and size explained only small amounts of variance in traits $(2.5-16.5 \%)$ and herbivory $(\leq 4 \%)$, indicating subindividual variability had low spatial predictability. The data suggest individual $P$. polytrichum plants represent heterogeneous and spatially unpredictable landscapes of physical traits and that interactions with herbivores are similarly variable. Our results are consistent with the hypothesis that subindividual variability defends plants against herbivores by increasing the difficulty of foraging for high-quality tissue.
\end{abstract}

Key words: intraspecific trait variation; herbivory; Piper polytrichum; Piperaceae; plant defense; plant subindividual variability 


\section{INTRODUCTION}

Over the past two decades there has been a surge of appreciation for the ecological importance of intraspecific trait variation, typically thought of as variation among individuals within a species (Bolnick et al. 2011). Plants are no exception to this trend: recent meta-analyses indicate that intraspecific trait variation can constitute up to $50 \%$ of the total trait variation found across entire plant communities (Messier et al. 2010; Siefert et al. 2015). For plants, however, a small and growing number of studies show that more than half of the total trait variation within species occurs not among individuals, but instead among homologous organs within plants (Herrera 2009). For example, $74.7 \%$ of the variation in pubescence within sessile oak (Quercus petraea) occurs spatially within individual trees rather than among individuals or populations (Bruschi et al. 2003). Such fine-scale variability means that an insect interacting with a plant could experience most of the entire range of a species' intraspecific trait variation without ever leaving an individual plant. Plant variability has a variety of potential effects on insects including reducing performance or altering population dynamics via nonlinear averaging (Karban et al. 1997; Wetzel et al. 2016) or time-sensitive, physiological effects (Koussoroplis et al. 2017; Pearse et al. 2018); altering insect movement behavior via resource concentration or dilution effects (Root 1973; Underwood et al. 2014); and increasing susceptibility of herbivores to predators via increased movement (Schultz 1983a) and the costs of repeated re-acclimation (Wetzel and Thaler 2016). Despite our understanding of the potential effects of subindividual plant variation and the growing number of empirical studies quantifying subindividual variability, our empirical understanding of the ecological consequences of subindividual variability lags behind (Herrera 2009). 
A key limitation in our understanding of the consequences of subindividual plant trait variability is that few studies have linked patterns of subindividual variation in plant defenses to species interactions, such as herbivory. This is a major shortcoming in our understanding of plant-animal interactions because plant subindividual variability has been shown to be heritable in some species, indicating that subindividual variability is itself a phenotypic axis that may play an evolutionary role (Herrera 2009, 2017; Herrera et al. 2017; Alonso et al. 2018). In one of the few field examples of how subindividual variability influences an antagonistic interaction, Shimada et al. (2015) showed that granivorous mice preferred to forage from oak trees (Quercus serrata) with high variability in seed mass and low variability in seed tannin content, indicating that among-seed variability could be a key trait mediating granivory. Surprisingly, very little research has examined this type of relationship for leaf traits and herbivory by folivores. This dearth exists despite the growing number of studies showing subindividual leaf variability and the many studies showing insects discriminate among leaf types within plants (Whitham 1978; Faeth 1991; Herrera 2009). Moreover, studies spanning multiple plant species have shown that dispersed herbivore leaf damage is less costly to plants than concentrated damage (Marquis 1992, 1996; Meyer 1998), suggesting that subindividual trait variability could benefit plant fitness simply by spreading out herbivore feeding. Field data on how subindividual leaf trait variability relates to the total amount of herbivory a plant receives and the distribution of herbivory among leaves within plants would advance our understanding of the causes and consequences of subindividual leaf variability for plant-herbivore interactions.

A second limitation in our understanding of how subindividual plant variability influences herbivory is that virtually all studies on this topic to date have been conducted in temperate systems (Herrera 2009, 2017), with depauperate data from tropical plants. Past work on within- 
plant patterns of defense in tropical plants has focused on how defenses change with leaf ontogeny (e.g., Coley et al. 2005) but has not examined variance in traits among leaves of a single ontogenetic stage or partitioned variance into among- and within-plant components. This is a key knowledge gap because plant-herbivore interactions are often found to differ between tropical and temperate systems (Coley and Barone 1996; Anstett et al. 2016). In temperate systems, subindividual variability may benefit plants by 'hiding' susceptible plant parts among well-defended parts. Such a strategy may be less effective in the tropics, where the relatively lower temporal environmental variability and generally higher herbivore densities (Salazar and Marquis 2012) may increase the likelihood that herbivores find all susceptible plant parts (Coley and Barone 1996), regardless of the presence of subindividual variability. Alternatively, the presence of stronger interactions between plants and herbivores in the tropics could favor subindividual variability there to a greater degree than in the temperate zone, if this variability reduces the fitness costs of herbivory to plants. Studies of subindividual plant variability and herbivory in tropical systems would broaden our understanding of the role of subindividual variability in the ecology and evolution of plant defense, potentially honing long-standing hypotheses that focus on tropical-temperate comparisons but have hitherto overlooked subindividual variability.

With these goals in mind, we quantified the within-plant variability of three physical leaf traits in Piper polytrichum (Piperaceae), a tropical understory shrub in Central America, and related this subindividual trait variability to leaf damage by chewing insect herbivores. Specifically, we focused on leaf toughness, trichome density, and leaf size, and quantified traits across leaves of different architectural positions. We asked three main questions: (1) What is the relative amount of variance in traits and herbivory within and among plants within a population? 
(2) How are trait values and herbivore damage distributed spatially within plants? (3) What factors, including both trait means and variances, explain the distribution of herbivore damage within and among plant individuals?

\section{MATERIALS AND METHODS}

We studied Piper polytrichum at the Organization for Tropical Studies Las Cruces Biological Station outside San Vito, Costa Rica ( $8^{\circ} 47^{\prime} 7^{\prime \prime}$ N, $82^{\circ} 57^{\prime} 32^{\prime \prime}$ W). Our site was a premontane wet forest at around $1200 \mathrm{~m}$. P. polytrichum is found across Costa Rica and Panama and was common in the understory at Las Cruces. Past studies with other Piper species have shown that chewing damage substantially reduces plant fitness (Marquis 1984) and that those reductions are smaller for dispersed damage than for spatially concentrated damage (Marquis 1992; Riberiro Mello 2007). These results suggest that subindividual trait variation in Piper could benefit plant fitness if it induced herbivores to feed more variably within plants. Those studies, however, did not compare the magnitude of subindividual variance in herbivore damage to the magnitude of among-plant variance or relate herbivore damage to subindividual plant trait variance, limiting our understanding of how plant variability influences variability in herbivory.

On 18 January 2015, we selected 23 P. polytrichum individuals (0.6-1.2 $\mathrm{m}$ height) along a transect through a single population and measured four leaves per plant. Within a plant, we started with the youngest fully expanded leaf ( $\geq 40 \mathrm{~mm}$ in width) and continuing proximally through the second, third, and fourth youngest fully-expanded leaves within the same branch, giving us four adjacent leaves in a sequence along a single branch. Selecting leaves in this way let us look at how traits and herbivory vary within the architecture of a plant, a variable encapsulating multiple factors including leaf ontogeny, age, and vascular position. Our approach 
let us quantify within-plant variability at a relatively fine scale, a scale that is relevant for the many species of insect herbivores that move among leaves on a plant as they feed. Moreover, studies indicate that most subindividual variance occurs within, rather than among, branches, and that most subindividual variance occurs simultaneously on plants, rather than sequentially through time (Herrera 2009). This suggests that we would not be missing significant trait variability by sampling leaves from only one branch per plant at only one point in time. We focused on fully expanded leaves because generally more is known about differences between expanding and fully expanded leaves than about variance within fully expanded leaves (Coley 1980, 1983; Coley et al. 2005).

For each leaf, we recorded toughness, trichome density, leaf width, percent leaf area removed by chewing herbivores, and leaf architectural position. Toughness and trichome density are key traits that have been shown in many plant species to be important defenses against leafchewing herbivores (Levin 1973; Raupp 1985; Hanley et al. 2007; Carmona et al. 2010). We measured toughness three times per leaf: once in the middle of the leaf (adjacent to but not touching the midrib), and half way between the midrib and either leaf edge, avoiding damaged tissue. We used a 600-g Pesola Medio Line spring scale tipped with a 5-mm hexagonal nut (Pesola AG, Schindellegi, Switzerland). We measured trichome density by counting trichomes along a 2-cm transect latitudinally across the widest part of the leaf using a hand lens, again avoiding damaged tissue. Leaf size was the leaf width at the widest point. Finally, we visually estimated percent leaf damage from herbivory, which was mainly from larval Lepidoptera and leaf beetles; we saw no evidence of damage from leaf-cutting Hymenoptera, leaf miners, or other herbivores with unique feeding patterns. 
We examined the relative amounts of within- and among-plant variance in all four response variables in three ways. First, we fit linear random effects models (LMMs) for each trait with a random effect for plant identity using the nlme package in R (Pinheiro et al. 2017; RCore-Team 2017). These models allowed us to partition total trait variance across the population of plants to among-plant and within-plant components. When partitioning variance among scales, measurement error is necessarily encompassed by the finest scale of observation. For leaf toughness, which is thought to have notable measurement error, we used our multiple measurements per leaf and included a random effect for leaf identity. The leaf-level random effect isolated measurement error from within-plant, among-leaf variance, moving it to the within-leaf scale. Second and third, we calculated the coefficient of variation and standard deviation for each variable at each scale, as a complementary method to quantify and compare variability. For all analyses we checked for normality, log transformed trichome counts, and square root arcsine transformed proportion leaf damage.

Second, we examined the within-plant distribution of trait values (toughness, trichome density) and herbivore damage in relation to leaf position and leaf size. We did this using LMMs with leaf position or leaf width as fixed effects and plant identity as a random effect. We tested the hypothesis that the responses varied with leaf position or leaf size by comparing each of these models to respective intercept-only null models using likelihood ratio tests (Bolker et al. 2009). For each model we summarize the proportion of total variance explained by leaf position and leaf size using marginal $R^{2}$ values calculated using the piecewiseSEM package in $\mathrm{R}$ (Lefcheck 2016).

We searched for trait means and variances that predicted herbivore damage among and within individual plants using random forests in the randomForest package in $\mathrm{R}$ (Liaw and 
Wiener 2002). For damage at the among-plant scale, our response was mean herbivore damage across the four measured leaves per plant, and the predictors in our full model were the means and standard deviations in toughness, trichome density, and leaf width across the four measured leaves per plant. For damage at the subindividual scale, our response was herbivore damage on each leaf, and the predictors in our full model were mean toughness of that same leaf across the three within-leaf measurements, variance in toughness across the three within-leaf measurements, trichome density, leaf position, and leaf width. We followed up the random forest analyses by fitting bivariate linear models with herbivore damage as the response and each of the above predictor variables.

\section{RESULTS}

Relative amount of among-plant and within-plant trait variance-We found substantial variation in all traits and herbivory (Table 1). The variance partitioning analyses indicated that more than half of all variance in each variable measured occurred within, rather than among, individual plants. The trait with the greatest proportion of within-plant variance was leaf toughness, for which a remarkable $97.0 \%$ of variance occurred within individual plants, with $32.6 \%$ occurring among leaves within plants and $64.4 \%$ occurring among measurements within leaves, leaving only 3\% to represent differences among plants (Fig. 1a). Slightly more than half of all variance in trichome density (56.9\%) and leaf width (60.9\%) occurred within plants (Fig. $1 b, c)$. As with the phenotypic traits, herbivore damage variability also occurred mostly within plants - about twice as much variance in herbivory occurred among leaves with plants (73.5\%) as among plants $(26.5 \%)$ (Fig. 1d). 
The variance partitioning analysis was largely confirmed by the standard deviations and coefficients of variation at each scale (Table 1). These measures of variation were similar at within- versus among-plant scales for all variables except leaf toughness, indicating about half of the total variance occurred within plants. Variability in leaf toughness was considerably larger within plants than among plants $(\mathrm{CV}=17.4 \%$ vs. $10.4 \%)$, as it was in the variance partitioning analysis.

Within-plant distribution of trait values and herbivory - We found that leaf architectural position explained statistically significant but small proportions of variance in leaf toughness and trichome density. Leaf position explained $16.5 \%$ of the variation in toughness $\left(\chi^{2}=17.8, d f=3\right.$, $P<0.01$ ), leaving $83.5 \%$ of the variation in toughness unexplained (Fig. 2a). Leaf position explained only $9.2 \%$ of the variation in trichome density $\left(\chi^{2}=17.8, d f=3, P<0.01\right)$ (Fig. 2 b) and was not predictive of herbivory $\left(\chi^{2}=4.6, d f=3, P=0.21, R^{2}=3.6 \%\right.$ ) (Fig. $2 \mathrm{c}$ ) or leaf size $\left(\chi^{2}=6.7, d f=3, P=0.083, R^{2}=4.4 \%\right)$, although the most apical and therefore youngest leaf tended to be smaller (Fig. 2d). Leaf traits and herbivory were also not well explained by leaf size. Leaf size only explained $2.5 \%$ of variation in leaf toughness $\left(\chi^{2}=2.2, d f=1, P=0.14\right), 9.0 \%$ of variation in trichome density $\left(\chi^{2}=9.5, d f=1, P<0.01\right)$, and $4.0 \%$ of variation in herbivore damage $\left(\chi^{2}=3.2, d f=1, P=0.075\right)$.

Predictors of herbivore damage - Plant means and among-leaf variances in leaf toughness, trichome density, and leaf width were not predictive of the total herbivory received by a plant. The random forest analysis including these variables explained an estimated $0 \%$ of the variation in damage among plants. Similarly, at the scale of individual leaves, the random forest analysis with toughness, variance in toughness, trichome density, and leaf width explained an estimated $0 \%$ of the variation in damage among leaves. Moreover, none of these individual variables 
significantly predicted leaf damage at the plant scale in general linear models or at the leaf scale in the bivariate linear mixed models.

\section{DISCUSSION}

Our results indicate that most of the variance in physical leaf traits in Piper polytrichum occurs among leaves within individual plants. Surprisingly, only small proportions of the total subindividual variation in traits or herbivore damage varied predictably within the architecture of a plant or with leaf size. Moreover, the distribution of herbivore chewing damage among plants was not predicted by plant-scale trait means or trait variances. Below, we compare the levels and patterns of subindividual trait variation in P. polytrichum with those found in other plant species and discuss implications of our principal finding that subindividual variance in traits and damage is both great in magnitude, and also spatially unpredictable.

Subindividual trait variation - The high proportion (57-97\%) of subindividual variance that we found for toughness, trichome denity, and leaf size in P. polytrichum is comparable to the results of other studies that have partitioned plant trait variance into within- and among-plant components. In a review of such studies, Herrera (2009) found that an average of $70.2 \%$ of variance in a number of traits, including toughness, leaf size, pubescence, and others, across the 16 temperate species occurred within individuals. For example, one of these studies found that in mountain birch (Betula pubescens ssp. Tortuosa) $88.0 \%$ of variance in toughness occurred within plants (Suomela and Ayres 1994), suggesting that it may be common for nearly all populationlevel variance in toughness to be present within individual plants. Such high values of subindividual variance in toughness are especially striking because both our study and the Suomela and Ayres (1994) study only measured traits on fully expanded leaves. Subindividual 
variance in toughness would certainly be even higher if measurements included expanding leaves, as the process of leaf expansion necessarily constrains cuticular thickening (Aide 1993). The key point is that tropical $P$. polytrichum has similarly high levels of subindividual trait variability relative to previously studied, predominantly temperate plant species.

A notable feature of subindividual variability from our study and others is high variance in toughness even within single leaves: sub-leaf variability constituted $64.6 \%$ of variance in our study and $46 \%$ of variance in the previously mentioned study of mountain birch (Suomela and Ayres 1994). Some of this within-leaf variance could be random spatial variation, but much of it is likely due to spatial patterns in toughness in relation to leaf structure. For example, leaf vein type and density are closely linked to mechanical properties, such as laminar strength (Kawai and Okada 2016), and such attributes of venation typically vary between basal, distal, and marginal regions of leaves (Hickey 1973). Some of the within-leaf variance is also likely due to measurement error, an inseparable component of the finest scale of measurement. However, even if one assumes that all within-leaf variance is simply measurement error and excludes it from estimates of subindividual variance, then subindividual variance in leaf toughness is still extremely high: this would be, by our calculation, $91.6 \%$ of variance in $P$. polytrichum and $77.8 \%$ of variance in the mountain birch study (Suomela and Ayres 1994). Indeed, this finding conforms to studies of other plant traits, including secondary metabolite concentration, that show high within-leaf variance in defensive traits (Shelton 2005).

Predictability of trait variation - We found that even though $P$. polytrichum had high levels of subindividual leaf trait variability, a low proportion of that variation $(2.5-16.5 \%)$ was predicted by leaf position or leaf size. We examined these two key structural variables because they encapsulate leaf ontogeny, vascular position, spatial position, abiotic conditions, and other 
factors; however, our results suggest that leaves located at different architectural positions or of differing sizes, among fully expanded leaves, do not have consistently different trait values. The relationship with the highest predictability was leaf position, which explained $16.5 \%$ of variance in leaf toughness, with leaves in the first nodal position (most distal, youngest) being slightly less tough on average than leaves in positions $2-4$. This suggests that chewing insects could, to a small extent, increase their chances of selecting a supple leaf by focusing their attack on distal fully expanded leaves; however, there was substantial overlap (83.5\%) in the ranges of toughness of leaves across distal and basal positions, making leaf position a relatively poor predictor of toughness and potentially making foraging difficult for chewing herbivores. Other studies have found that species may exhibit high (Herrera et al. 2015) or low (Schultz 1983b) predictability in subindividual trait variance — but that unpredictable variation at fine scales is often the dominant form of subindividual plant variation (Herrera 2009). Overall, P. polytrichum, seems to corroborate this pattern of high, but unpredictable subindividual leaf trait variation.

Implications of variability and unpredictability for herbivory - One of the key implications from our trait results is that insect herbivores feeding on $P$. polytrichum face astounding spatial variability and unpredictability in leaf traits at small scales. This observation is consistent with the hypothesis that subindividual plant variability could itself be a defensive phenotype against attack by insect herbivores (Karban et al. 1997; Herrera 2009). This high variability and low predictability also suggests that the spatial unit relevant for plant-herbivore interactions may not be the plant individual, but instead may be patches of suitable tissue within individuals. Such fine-scale trait variability—combined with its low predictability across leaf position and size—-likely makes foraging more difficult for insect herbivores. Given that architecture, leaf size, and factors correlated with them are key cues available to chewing 
herbivores for leaf selection during foraging, our results suggest that the weak relationship between leaf position, leaf size, and other variables may make finding the best leaf tissue difficult. If high quality tissue were predictably distributed within plants, then foraging herbivores would only need to move directly to the locations that reliably have high quality tissue. If high quality tissue were unpredictably distributed within plants, as it is in $P$. polytrichum, then herbivores would need to search more intensively, sampling from multiple leaves or plants before finding adequate tissue, thus wasting time and energy and potentially consuming well-defended, toxic tissue during the search. The uncertainty around the locationand existence — of high-quality tissue during foraging, moreover, could cause herbivores to settle for relatively low-quality, well-defended tissue before finding high-quality, undefended leaves, or to leave a plant altogether.

Linking patterns of trait variability to herbivore damage - Even though multiple studies have examined subindividual patterns of leaf trait variation, very few studies have related these patterns to variance in herbivory. We found for leaf damage the magnitude of subindividual variability and unpredictability was strikingly similar to our results for leaf traits. A surprisingly high amount $(73.5 \%)$ of the total variance in herbivory occurred among leaves within individual plants, rather than among plants within the population. Moreover, neither leaf architectural position nor leaf size had significant relationships with damage. These results are consistent with the hypothesis that subindividual plant trait variability makes foraging difficult for insect herbivores, creating fine-grained patches of varying tissue quality that cause herbivores to feed in a similarly heterogeneous manner. Inducing herbivores to feed patchily could directly reduce herbivore growth and survival via costs associated with movement, sampling low quality tissue, settling for low quality tissue due to lack of information, and other factors. In addition, patchy 
feeding could indirectly reduce herbivore survival by increasing the vulnerability of herbivores to their predators. This could occur because movement makes herbivores more apparent to predators (Schultz 1983a), or because plant variability forces herbivores to repeatedly acclimate physiologically to plant tissue of differing quality. Acclimation requires time and energy and may constrain how and when herbivores can defend against predators (Wetzel and Thaler 2016).

There are at least three potential reasons why the distribution of herbivore damage in $P$. polytrichum was not related to any of the leaf trait variables we measured, at the leaf scale or at the plant scale ( $0 \%$ variance explained in both random forest analyses). First, high subindividual plant trait variability and unpredictability may make foraging so difficult or costly that the correlation between tissue quality and feeding damage is broken or weakened—causing herbivores to feed on tough, defended tissue while tender, less-defended tissue on the same plant remains unused. This is essentially an extension of the more general hypothesis, discussed above, that subindividual variability is difficult for insect herbivores. This effect could arise through at least two mechanisms: insect sensory limitations, which may make insects simply unable to find high quality tissue effectively in complex environments (Bernays 1999, 2001); or the high costs of moving among high quality patches, such that it may be most efficient in variable plant environments for insects to settle for mediocre tissue available locally, rather than pursuing the highest quality tissue overall (Charnov 1976). If subindividual variability negatively affected herbivore foraging these ways, we would expect to see less damage on more variable plants, which is not what we observed. Our ability to find a relationship between subindividual variability and damage, however, may have been limited because the magnitude of trait variance was similar among most plants in this population. Nonetheless, even if variability in defensive traits does not reduce total herbivory, it could simply make herbivory variable within plants, 
which, as discussed above, has been shown to reduce the fitness costs of herbivory in other Piper species (Marquis 1992; Riberiro Mello 2007). Indeed, we found $73.5 \%$ of the total variance in herbivore damage occurred within plants. Here, we did find that the scale at which plant traits are most variable (the subindividual scale) was also the scale at which herbivory was most variable, in coarse agreement with this hypothesis.

A second potential reason for the weak relationship between herbivore damage and plant traits is simply that the traits we measured—leaf toughness and trichome density—are of minimal importance to chewing herbivores on $P$. polytrichum. Indeed, secondary chemistry is known to be important for herbivory on other species in the genus Piper (Richards et al. 2015; Glassmire et al. 2016) and could be driving herbivory in P. polytrichum. Physical traits, however, have been shown to be key predictors of herbivory across many systems (Hanley et al. 2007; Carmona et al. 2010). Trichome density, specifically, has been shown to influence many specialist and generalist chewing herbivores from different orders with different life histories, and is itself often correlated with secondary chemistry (Levin 1973; Tian et al. 2012). Leaf toughness has been shown to lead to mandibular wear and slow feeding of chewing herbivores (Raupp 1985). Finally, our finding that damage was not related to leaf size or architectural position, which can be correlated with secondary chemistry and other traits of importance to insect herbivores, further suggests that herbivores are feeding patchily and potentially randomly with respect to traits within plant individuals.

Third, the reason for the lack of clear relationship between plant traits and herbivory could be that we can only measure traits on remaining, unconsumed tissue. In other words, it is possible that the tissue that was consumed by herbivores, which we were unable to measure, had significantly different toughness and trichome density than measured tissue. If this were true, it 
would mean that our calculated values of subindividual trait variance would likely be underestimates because herbivory would have obscured the extremes of toughness and trichome density, by removing the extreme tissue from the plant. Moreover, given the high within-plant variance we found in herbivory, if this were true, it would suggest that there would also be high subindividual variance in the presence of this hypothesized high-quality tissue. If anything, this finding would further support the notion that $P$. polytrichum has high subindividual variance in quality and subsequently in herbivory.

Conclusion-We found that most variance in physical leaf traits in a tropical shrub occurred within individual plants. Moreover, this high level of subindividual variability was mirrored by patterns of leaf damage by chewing herbivores. Subindividual trait variability could arise because it is difficult for plants to build or maintain leaves without variation among them. Alternatively, subindividual trait variation could enhance plant fitness, incurring costs to herbivores and/or distributing herbivory in a less harmful way, and be selected for and maintained across both tropical and temperate systems. Subindividual plant variation is potentially relevant across a multitude of ecological and evolutionary contexts, and we advocate for its consideration within the array of plant traits commonly considered drivers of plantherbivore interactions across ecosystems.

\section{Acknowledgments}

We thank the Las Cruces Biological Station for logistical help and Moria Robinson, Eric LoPresti, and Carina Baskett for helpful comments that greatly improved the manuscript.

\section{Author contributions}


WW and MM conceived, designed, and carried out the study and wrote the manuscript.

\section{Data accessibility}

The data in this manuscript are available online at the Dryad Digital Repository (TBD).

\section{Literature cited}

Aide, T.M. 1993. Patterns of leaf development and herbivory in a tropical understory community. Ecology, 74(2): 455-466.

Alonso, C., Pérez, R., Bazaga, P., Medrano, M., and Herrera, C.M. 2018. Within-plant variation in seed size and inflorescence fecundity is associated with epigenetic mosaicism in the shrub Lavandula latifolia (Lamiaceae). Ann. Bot. 121(1): 153-160. doi:10.1093/aob/mcx140.

Anstett, D.N., Nunes, K.A., Baskett, C., and Kotanen, P.M. 2016. Sources of controversy surrounding latitudinal patterns in herbivory and defense. Trends Ecol. Evol. 31(10): 789802. doi:10.1016/j.tree.2016.07.011.

Bernays, E.A. 1999. When host choice is a problem for a generalist herbivore: experiments with the whitefly, Bemisia tabaci. Ecol. Entomol. 24: 260-267.

Bernays, E.A. 2001. Neural limitations in phytophagous insects: implications for diet breadth and evolution of host affiliation. Annu. Rev. Entomol. 46(1): 703-727.

Bolker, B.M., Brooks, M.E., Clark, C.J., Geange, S.W., Poulsen, J.R., Stevens, M.H.H., and White, J.-S.S. 2009. Generalized linear mixed models: a practical guide for ecology and evolution. Trends Ecol. Evol. 24(3): 127-135.

Bolnick, D.I., Amarasekare, P., Araújo, M.S., Bürger, R., Levine, J.M., Novak, M., Rudolf, 
V.H.W., Schreiber, S.J., Urban, M.C., and Vasseur, D.A. 2011. Why intraspecific trait variation matters in community ecology. Trends Ecol. Evol. 26(4): 183-192.

Bruschi, P., Grossoni, P., and Bussotti, F. 2003. Within- and among-tree variation in leaf morphology of Quercus petraea (Matt.) Liebl. natural populations. Trees, 17: 164-172. doi:10.1007/s00468-002-0218-y.

Carmona, D., Lajeunesse, M.J., and Johnson, M.T.J. 2010. Plant traits that predict resistance to herbivores. Funct. Ecol. 25(2): 358-367.

Charnov, E.L. 1976. Optimal foraging, the marginal value theorem. Theor. Popul. Biol. 9(2): $129-136$.

Coley, P.D. 1980. Effects of leaf age and plant life history patterns on herbivory. Nature, 284: $545-546$.

Coley, P.D. 1983. Herbivory and defensive characteristics of tree species in a lowland tropical forest. Ecol. Monogr. 52(2): 209-234.

Coley, P.D., and Barone, J.A. 1996. Herbivory and plant defenses in tropical forests. Annu. Rev. Ecol. Syst. 27: 305-335. doi:10.1146/annurev.ecolsys.27.1.305.

Coley, P.D., Lokvam, J., Rudolph, K., Bromberg, K., Sackett, T.E., Wright, L., BrenesArguedas, T., Dvorett, D., Ring, S., and Clark, A. 2005. Divergent defensive strategies of young leaves in two species of Inga. Ecology, 86(10): 2633-2643.

Faeth, S.H. 1991. Effect of oak leaf size on abundance, dispersion, and survival of the leafminer Cameraria sp. (Lepidoptera: Gracillariidae). Environ. Entomol. 20(1): 196-204.

Glassmire, A.E., Jeffrey, C.S., Forister, M.L., Parchman, T.L., Nice, C.C., Jahner, J.P., Wilson, J.S., Walla, T.R., Richards, L.A., Smilanich, A.M., Leonard, M.D., Morrison, C.R., Simbaña, W., Salagaje, L.A., Dodson, C.D., Miller, J.S., Tepe, E.J., Villamarin-Cortez, S., 
and Dyer, L.A. 2016. Intraspecific phytochemical variation shapes community and population structure for specialist caterpillars. New Phytol. 212(1): 208-219. doi:10.1111/nph.14038.

Hanley, M.E., Lamont, B.B., Fairbanks, M.M., and Rafferty, C.M. 2007. Plant structural traits and their role in anti-herbivore defence. Perspect. Plant Ecol. Evol. Syst. 8(4): 157-178. doi:10.1016/j.ppees.2007.01.001.

Herrera, C.M. 2009. Multiplicity in Unity: Plant Subindividual Variation \& Interactions with Animals. University of Chicago Press, Chicago.

Herrera, C.M. 2017. The ecology of subindividual variability in plants: Patterns, processes, and prospects. Web Ecol. 17(2): 51-64. doi:10.5194/we-17-51-2017.

Herrera, C.M., Medrano, M., and Bazaga, P. 2015. Continuous within-plant variation as a source of intraspecific functional diversity: patterns, magnitude, and genetic correlates of leaf variability in Helleborus foetidus (Ranunculaceae). Am. J. Bot. 102(2): 225-232. doi:10.3732/ajb.1400437.

Herrera, C.M., Medrano, M., and Bazaga, P. 2017. Comparative epigenetic and genetic spatial structure of the perennial herb Helleborus foetidus: isolation by environment, isolation by distance, and functional trait divergence. Am. J. Bot. 104(8): 1195-1204. doi:10.5061/dryad.fr2k8.

Hickey, L.J. 1973. Classification of the architecture of dicotyledonous leaves. Am. J. Bot. 60(1): 17-33.

Karban, R., Agrawal, A.A., and Mangel, M. 1997. The benefits of induced defenses against herbivores. Ecology, 78(5): 1351-1355.

Kawai, K., and Okada, N. 2016. How are leaf mechanical properties and water-use traits 
coordinated by vein traits? A case study in Fagaceae. Funct. Ecol. 30(4): 527-536. doi:10.1111/1365-2435.12526.

Koussoroplis, A.M., Pincebourde, S., and Wacker, A. 2017. Understanding and predicting physiological performance of organisms in fluctuating and multifactorial environments. Ecol. Monogr. 87(2): 178-197. doi:10.1111/ijlh.12426.

Lefcheck, J.S. 2016. piecewiseSEM: Piecewise structural equation modelling in R for ecology, evolution, and systematics. Methods Ecol. Evol. 7(5): 573-579. doi:10.1111/2041210X.12512.

Levin, D.A. 1973. The role of trichomes in plant defense. Q. Rev. Biol. 48(1): 3-15.

Liaw, A., and Wiener, M. 2002. Classification and regression by randomForest. R news, 2(December): 18-22. doi:10.1177/154405910408300516.

Marquis, R.J. 1984. Leaf herbivores decrease fitness of a tropical plant. Science, 226: 537.

Marquis, R.J. 1992. A bite is a bite is a bite? Constraints on response to folivory in Piper arieianum (Piperaceae). Ecology, 73(1): 143-152.

Marquis, R.J. 1996. Plant architecture, sectoriality and plant tolerance to herbivores. Vegetatio, 127(1): 85-97.

Messier, J., McGill, B.J., and Lechowicz, M.J. 2010. How do traits vary across ecological scales? A case for trait-based ecology. Ecol. Lett. 13(7): 838-848. doi:10.1111/j.14610248.2010.01476.x.

Meyer, G.A. 1998. Pattern of defoliation and its effect on photosynthesis and growth of Goldenrod. Funct. Ecol. 12(2): 270-279. doi:10.1046/j.1365-2435.1998.00193.x.

Pearse, I.S., Paul, R., and Ode, P.J. 2018. Variation in plant defense suppresses herbivore performance. Curr. Biol. 28(12): 1981-1986. doi:10.1016/j.cub.2018.04.070. 
Pinheiro, J., Bates, D., DebRoy, S., Sarkar, D., and R-Core-Team. 2017. nlme: Linear and Nonlinear Mixed Effects Models. https:/CRAN.R-project.org/package=nlme.

R-Core-Team. 2017. R: A Language and Environment for Statistical Computing. R Foundation for Statistical Computing, Vienna, Austria.

Raupp, M.J. 1985. Effects of leaf toughness on mandibular wear of the leaf beetle, Plagiodera versicolora. Ecol. Entomol. 10(1): 73-79. doi:10.1111/j.1365-2311.1985.tb00536.x.

Riberiro Mello, M.A. 2007. Influence of herbivore attack patterns on reproductive success of the shrub Piper hispidum (Piperaceae). Ecotropica, 13(1): 1-6.

Richards, L.A., Dyer, L.A., Forister, M.L., Smilanich, A.M., Dodson, C.D., Leonard, M.D., and Jeffrey, C.S. 2015. Phytochemical diversity drives plant-insect community diversity. Proc. Natl. Acad. Sci. U.S.A. 12(35): 10973-10978. doi:10.1073/pnas.1504977112.

Root, R.B. 1973. Organization of a plant-arthropod association in simple and diverse habitats: the fauna of collards (Brassica oleracea). Ecol. Monogr. 43(1): 95-124. doi:10.2307/1942161.

Salazar, D., and Marquis, R.J. 2012. Herbivore pressure increases toward the equator. Proc. Natl. Acad. Sci. U.S.A. 109(31): 12616-12620. doi:10.1073/pnas.1202907109.

Schultz, J.C. 1983a. Impact of variable plant defensive chemistry on susceptibility of insects to natural enemies. In Plant Resistance to Insects. Edited by P. Hedin. American Chemical Society, Washington, DC. pp. 37-54.

Schultz, J.C. 1983b. Habitat selection and foraging tactics of caterpillars in heterogeneous trees. In Variable Plants and Herbivores in Natural and Managed Systems. Edited by R.F. Denno and M.S. McClure. Academic Press. pp. 61-90.

Shelton, A.L. 2005. Within-plant variation in glucosinolate concentrations of Raphanus sativus 
across multiple scales. J. Chem. Ecol. 31(8): 1711-1732. doi:10.1007/s10886-005-5922-9.

Shimada, T., Takahashi, A., Shibata, M., and Yagihashi, T. 2015. Effects of within-plant variability in seed weight and tannin content on foraging behaviour of seed consumers. Funct. Ecol. 29(12): 1513-1521. doi:10.1111/1365-2435.12464.

Siefert, A., Violle, C., Chalmandrier, L., Albert, C.H., Taudiere, A., Fajardo, A., Aarssen, L.W., Baraloto, C., Carlucci, M.B., Cianciaruso, M. V., de L. Dantas, V., de Bello, F., Duarte, L.D.S., Fonseca, C.R., Freschet, G.T., Gaucherand, S., Gross, N., Hikosaka, K., Jackson, B., Jung, V., Kamiyama, C., Katabuchi, M., Kembel, S.W., Kichenin, E., Kraft, N.J.B., Lagerström, A., Bagousse-Pinguet, Y. Le, Li, Y., Mason, N., Messier, J., Nakashizuka, T., Overton, J.M., Peltzer, D.A., Pérez-Ramos, I.M., Pillar, V.D., Prentice, H.C., Richardson, S., Sasaki, T., Schamp, B.S., Schöb, C., Shipley, B., Sundqvist, M., Sykes, M.T., Vandewalle, M., and Wardle, D.A. 2015. A global meta-analysis of the relative extent of intraspecific trait variation in plant communities. Ecol. Lett. 18(12): 1406-1419. doi:10.1111/ele.12508.

Suomela, J., and Ayres, M.P. 1994. Within-tree and among-tree variation in leaf characteristics of mountain birch and its implications for herbivory. Oikos, 70(2): 212-222.

Tian, D., Tooker, J., Peiffer, M., Chung, S.H., and Felton, G.W. 2012. Role of trichomes in defense against herbivores: comparison of herbivore response to woolly and hairless trichome mutants in tomato (Solanum lycopersicum). Planta, 236(4): 1053-1066. doi:10.1007/s00425-012-1651-9.

Underwood, N., Inouye, B.D., and Hambäck, P.A. 2014. A conceptual framework for associational effects: when do neighbors matter and how would we know? Q. Rev. Biol. 89(1): 1-19. 
Wetzel, W.C., Kharouba, H.M., Robinson, M., Holyoak, M., and Karban, R. 2016. Variability in plant nutrients reduces insect herbivore performance. Nature, 539: 425-427. doi:10.1038/nature20140.

Wetzel, W.C., and Thaler, J.S. 2016. Does plant trait diversity reduce the ability of herbivores to defend against predators? The plant variability-gut acclimation hypothesis. Curr. Opin.

Insect Sci. 14: 25-31. doi:10.1016/j.cois.2016.01.001.

Whitham, T.G. 1978. Habitat selection by Pemphigus aphids in response to resource limitation and competition. Ecology, 59(6): 1164-1176. 
Table 1. Variability in leaf toughness, trichome density, leaf width, and herbivore damage at three scales in Piper polytrichum.

\begin{tabular}{|c|c|c|c|c|c|c|c|c|c|c|c|c|}
\hline \multirow[t]{2}{*}{ Source } & \multicolumn{3}{|c|}{ Toughness } & \multicolumn{3}{|c|}{ Trichomes $^{a}$} & \multicolumn{3}{|c|}{ Leaf width } & \multicolumn{3}{|c|}{ Herbivory $^{b}$} \\
\hline & $\% \operatorname{var}^{c}$ & $\mu \pm \sigma^{d}$ & $\mathrm{CV}$ & $\%$ var & $\mu \pm \sigma$ & $\mathrm{CV}$ & $\%$ var & $\mu \pm \sigma$ & $\mathrm{CV}$ & $\%$ var & $\mu \pm \sigma$ & $\mathrm{CV}$ \\
\hline $\begin{array}{l}\text { Among } \\
\text { plants }\end{array}$ & 3.0 & $234.1 \pm 24.3$ & 10.4 & 43.1 & $22.1 \pm 5.5$ & 25.1 & 39.1 & $58.7 \pm 6.5$ & 11.1 & 26.5 & $0.20 \pm 0.14$ & 70.3 \\
\hline $\begin{array}{l}\text { Within } \\
\text { plants }\end{array}$ & 32.6 & \pm 40.2 & 17.4 & 56.9 & \pm 5.0 & 22.9 & 60.9 & \pm 6.2 & 10.8 & 73.5 & \pm 0.14 & 76.6 \\
\hline $\begin{array}{l}\text { Within } \\
\text { leaves }^{e}\end{array}$ & 64.4 & \pm 44.2 & 19.7 & - & - & - & - & - & - & - & - & - \\
\hline
\end{tabular}

${ }^{a}$ Trichome $\%$ var was calculated with log trichome density to achieve normality. $\sigma$ and CV were left on the raw scale to aid interpretability.

${ }^{b}$ Arcsine transformed herbivory.

${ }^{c}$ Percent variance in each variable attributable to each scale, estimated using random effects models (also shown in Fig. 1).

${ }^{d}$ Raw mean and mean of standard deviations across units at each scale. $\mu$ is the same across all scales and therefore is shown only for the first scale.

${ }^{e}$ Only toughness was measured repeatedly within leaves. 
Fig. 1. Toughness (grams of force), trichome density (count per $2 \mathrm{~cm}$ ), and herbivore damage (arcsine transformed proportional area damaged) for four leaves per plant from 23 Piper polytrichum plants in a single population. (a, c, e) Points for each plant from the youngest fully expanded leaf (grey dots), second leaf (orange triangles), third leaf (blue squares), and fourth leaf (green crosses). (b, d, f) The results of variance partitioning to scales of among plants, within plants, or within leaves for toughness, trichome density, and herbivore damage respectively. For toughness, there are multiple measurements per leaf.

Fig. 2. Leaf toughness (a), trichome density (b), herbivore damage (c), and width (d) as a function of leaf position in Piper polytrichum. Position 1 is the youngest, most distal fully expanded leaf, and positions 2-4 are the second through fourth most distal fully expanded leaves. Each gray point is one leaf, and the large orange points and lines show the means and 95\% confidence intervals estimated from models taking plant into account. Damage is arcsine transformed. 


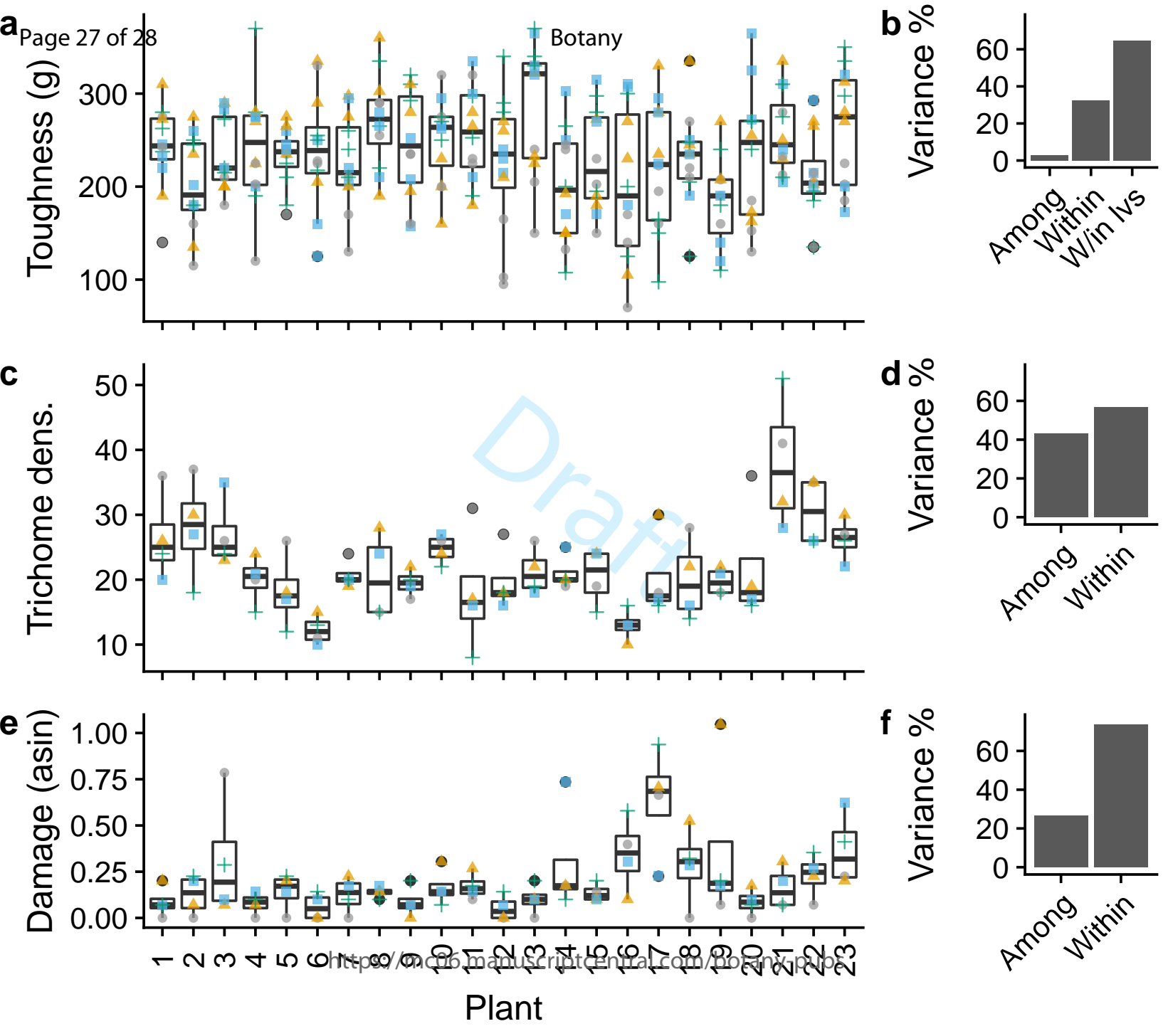


a $\widehat{D} 350-1$

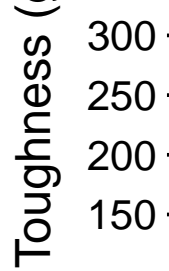
Botany

- Page $28 \circ$ of 28

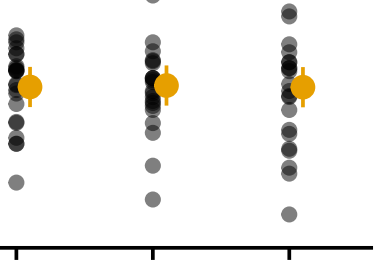

b ்ֻ 50 -

0

$\frac{0}{0} 40$

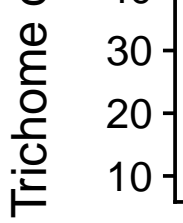

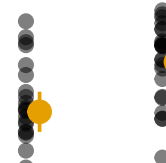

8

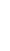

c $\stackrel{\widehat{I}}{\mathrm{~s}} 1.00-$

巴O 0.75

0.50

胥 0.25

d

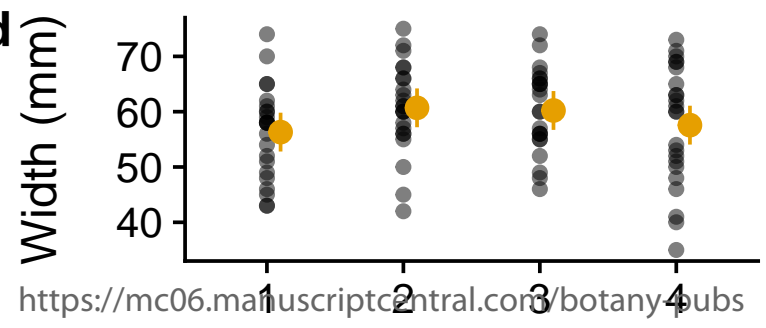

Leaf position 